\title{
Research on the assessment of psycholinguistic teaching effect with triangular fuzzy information
}

\author{
Qian Wang* \\ School of Foreign Languages, Northwestern Polytechnical University, Xi'an, China
}

\begin{abstract}
The effect and quality of education is the fundamental of higher education, and instructional reform is the core one of all reforms in higher education. In order to motivate the instructional reform and enhance the quality of education, the department of education in China has evaluated and rewarded the study performance in instructional practice of educators in higher learning instructions since 1989. This means has pushed enormously the process of the instructional reform in higher learning institutions and enhanced the effect and quality of higher education. However, evaluating and rewarding the excellent study performance of educators in higher learning institutions still depends on the qualitative evaluation by the expert's intelligence and experience. In this paper, we investigate the multiple attribute decision making problems for evaluating the psycholinguistic teaching effect with triangular fuzzy information. Motivated by the idea of geometric Bonferroni mean and Einstein operations, we develop the triangular fuzzy Einstein geometric Bonferroni mean (TFEGBM) operator and triangular fuzzy weighted Einstein geometric Bonferroni mean (TFWEGBM) operator for aggregating the triangular fuzzy information. Then, based on the TFWEGBM operator, we develop the procedure for multiple attribute decision making with the triangular fuzzy information. Finally, a practical example for evaluating the psycholinguistic teaching effect is given to verify the developed approach.
\end{abstract}

Keywords: Multiple attribute decision making, triangular fuzzy numbers, Geometric Bonferroni mean, triangular fuzzy Einstein geometric Bonferroni mean (TFEGBM) operator, triangular fuzzy weighted Einstein geometric Bonferroni mean (TFWEGBM) operator, psycholinguistic teaching effect

\section{Introduction}

Fuzzy multiple attribute decision making (FMADM) is an important part of modern decision science [1-4]. It assumes that there exists a set of alternatives with multiple attributes which a decision maker (DM) should evaluate and analyze. The aim of FMADM is to find the most desirable alternative or rank the feasible alternatives for supporting decision makings. As an active research area, FMADM

\footnotetext{
${ }^{*}$ Corresponding author. Qian Wang, School of Foreign Languages, Northwestern Polytechnical University, Xi'an, China. Tel./Fax: +86029 84350768; E-mail: xbgydxwq@163.com.
}

problems have been tried to be solved by some classical methods such as the simple additive weighting method (SAW), the analytic hierarchy process (AHP), and the technique for order preference by similarity to ideal solution (TOPSIS) [5-7]. Xu [8] and Fan and Wang [9] developed the fuzzy ordered weighted averaging (FOWA) operator. $\mathrm{Xu}$ [10] introduced the fuzzy ordered weighted geometric (FOWG) operator. $\mathrm{Xu}$ and $\mathrm{Wu}$ [11] proposed the fuzzy induced ordered weighted averaging (FIOWA) operator. $\mathrm{Xu}$ and $\mathrm{Da}$ [12] developed the fuzzy induced ordered weighted geometric (FIOWG) operator. Xu [13] developed the fuzzy weighted harmonic mean (FWHM) operator, fuzzy ordered 
weighted harmonic mean (FOWHM) operator, fuzzy hybrid harmonic mean (FHHM) operator. Wei [14] proposed the fuzzy ordered weighted harmonic averaging(FOWHA) operator. Wei [15] developed the fuzzy induced ordered weighted harmonic mean (FIOWHM) operator. Wei [16] proposed the generalized triangular fuzzy correlated averaging operator and applied these operators to multiple attribute decision making. Merigo [17] presented the fuzzy probabilistic ordered weighted averaging (FPOWA) operator. Merigo and Casanovas [18] presented the fuzzy generalized hybrid averaging (FGHA) operator, the fuzzy induced generalized hybrid averaging (FIGHA) operator, the Quasi-FHA operator and the Quasi-FIHA operator. Merigo and Gil-Lafuente [19] proposed the fuzzy induced generalized ordered weighted averaging (FIGOWA) and the fuzzy induced quasi-arithmetic OWA (Quasi-FIOWA) operator. Xu [20] developed some fuzzy ordered distance measures, such as linguistic ordered weighted distance measure, uncertain ordered weighted distance measure, linguistic hybrid weighted distance measure, and uncertain hybrid weighted distance measure, etc. Zhao et al. [21] proposed fuzzy prioritized operators for multiple attribute group decision making. Wei et al. [22] proposed fuzzy power aggregating operators for multiple attribute group decision making. Zhu et al. [23] developed the triangular fuzzy weighted Bonferroni mean (TFWBM) operator for multiple attribute decision making under the triangular fuzzy environments. Guo et al. [24] developed the triangular fuzzy geometric Bonferroni mean (TFGBM) operator and triangular fuzzy weighted geometric Bonferroni mean (TFWGBM) operator, based on which we design two procedure for multiple attribute decision making under the triangular fuzzy environments.

As a powerful method which improves classteaching effect, the students' evaluation of the class-teaching effect has become more and more important in recent years in universities of China. It plays an important role in improving instruction, teachers' job evaluation, promoting rewards and punishments. However because of the congenital deficiency of the students' evaluation of the class-teaching effect, it restricts seriously the exertion of the function in diagnosing and stimulating. There are some discontented phenomena in universities, such as some universities have to stop the practice on account of all aspects pressure which can't endure, some universities limit the practice to form while the evaluation's result is laid aside, some universities only reward little efficacy. There are many factors which effect the exertion of the function of the students' evaluation of the class-teaching effect. Considering the subject and the object of evaluation, it involves the cognitive aspect of teachers and students, the mental adjustment and so on. Considering the process of evaluation, it involves publicity of the purpose and significance, the design of the index system, the establishment and implementation of evaluation scheme, the data's disposal and implication. In this paper, we investigate the multiple attribute decision making problems for evaluating the psycholinguistic teaching effect with triangular fuzzy information. Motivated by the traditional idea of geometric Bonferroni mean [25-27] and Einstein operations [28-32], we develop the triangular fuzzy Einstein geometric Bonferroni mean (TFEGBM) operator and triangular fuzzy weighted Einstein geometric Bonferroni mean (TFWEGBM) operator for aggregating the triangular fuzzy information. Then, based on the TFWEGBM operator, we develop the procedure for multiple attribute decision making with the triangular fuzzy information. Finally, a practical example for evaluating the psycholinguistic teaching effect is given to verify the developed approach.

\section{Preliminaries}

In this section, we briefly describe some basic concepts and basic operational laws related to triangular fuzzy numbers.

Definition 1. [33] A triangular fuzzy numbers $\tilde{a}$ can be defined by a triplet $\left(a^{L}, a^{M}, a^{U}\right)$. The membership function $\mu_{\tilde{a}}(x)$ is defined as:

$$
\mu_{\tilde{a}}(x)= \begin{cases}0, & x<a^{L}, \\ \frac{x-a^{L}}{a^{M}-a^{L}}, & a^{L} \leq x \leq a^{M}, \\ \frac{x-a^{U}}{a^{M}-a^{U}}, & a^{M} \leq x \leq a^{U}, \\ 0, & x \geq a^{U} .\end{cases}
$$

where $0<a^{L} \leq a^{M} \leq a^{U}, a^{L}$ and $a^{U}$ stand for the lower and upper values of the support of $\tilde{a}$, respectively, and $a^{M}$ for the modal value.

Definition 2. [33] Basic operational laws related to triangular fuzzy numbers:

$$
\begin{aligned}
\tilde{a} \oplus \tilde{b} & =\left[a^{L}, a^{M}, a^{U}\right] \oplus\left[b^{L}, b^{M}, b^{U}\right] \\
& =\left[a^{L}+b^{L}, a^{M}+b^{M}, a^{U}+b^{U}\right]
\end{aligned}
$$




$$
\begin{aligned}
\tilde{a} \otimes \tilde{b} & =\left[a^{L}, a^{M}, a^{U}\right] \otimes\left[b^{L}, b^{M}, b^{U}\right] \\
& \approx\left[a^{L} b^{L}, a^{M} b^{M}, a^{U} b^{U}\right] \\
\lambda \otimes \tilde{a} & =\lambda \otimes\left[a^{L}, a^{M}, a^{U}\right] \\
& =\left[\lambda a^{L}, \lambda a^{M}, \lambda a^{U}\right], \lambda>0 .
\end{aligned}
$$

Definition 3. [13] Let $\tilde{b}=\left[b^{L}, b^{M}, b^{U}\right]$ and $\tilde{a}=$ $\left[a^{L}, a^{M}, a^{U}\right]$ be two triangular fuzzy numbers, then the degree of possibility of $a \geq b$ is defined as

$$
\begin{aligned}
& p(a \geq b) \\
& =\lambda \max \left\{1-\max \left[\frac{b^{M}-a^{L}}{a^{M}-a^{L}+b^{M}-b^{L}}, 0\right], 0\right\} \\
& +(1-\lambda) \max \left\{1-\max \left[\frac{b^{U}-a^{M}}{a^{U}-a^{M}+b^{U}-b^{M}}, 0\right], 0\right\}
\end{aligned}
$$

Einstein operations [28] includes the Einstein product and Einstein sum, which are examples of tnorms and tconorms, respectively. Einstein product $\otimes_{\varepsilon}$ is a t-norm and Einstein sum $\oplus_{\varepsilon}$ is a t-conorm, where

$$
\begin{aligned}
a \oplus_{\varepsilon} b= & \frac{a+b}{1+a \cdot b}, \\
a \otimes_{\varepsilon} b= & \frac{a \cdot b}{1+(1-a) \cdot(1-b)}, \\
& \forall(a, b) \in[0,1]^{2} .
\end{aligned}
$$

In the following, Zhu et al. [25] studied on the geometric Bonferroni mean (GBM).
Definition 4. [25] Let $p, q \geq 0$ and $a_{i}(i=1,2$, $\cdots, n)$ refers to a collection of non-negative real numbers. Afterwards, the aggregation functions

$$
\begin{aligned}
G B M^{p, q}\left(a_{1}, a_{2}, \cdots, a_{n}\right) \\
=\frac{1}{p+q}\left(\prod_{\substack{i, j=1 \\
i \neq j}}^{n}\left(p a_{i}+q a_{j}\right)\right)^{\frac{1}{n(n-1)}}
\end{aligned}
$$

is called the geometric Bonferroni mean (GBM) operator.

\section{Triangular fuzzy Einstein geometric Bonferroni mean operators}

The geometric Bonferroni mean [25-27] and Einstein operations [28-32], however, have usually been used in situations where the input arguments are the non-negative real numbers. We shall extend the GBM operators and Einstein operations to accommodate the situations where the input arguments are triangular fuzzy numbers. In this section, we shall investigate the GBM operators and Einstein operations under triangular fuzzy environments. Then, we shall propose the triangular fuzzy Einstein geometric Bonferroni mean (TFEGBM) operator as follows:

Definition 5. Let $\tilde{a}_{i}=\left[a_{i}^{L}, a_{i}^{M}, a_{i}^{U}\right](i=1,2, \cdots, n)$ be a set of triangular fuzzy numbers, and let $p, q>0$. If

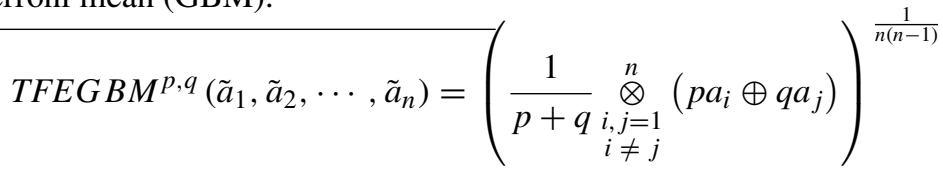

$$
\begin{aligned}
& =\left[\frac{1}{p+q}\left(\prod_{\substack{i, j=1 \\
i \neq j}}^{n}\left(p a_{i}^{L}+q a_{j}^{L}\right)\right)^{\frac{1}{n(n-1)}}, \frac{1}{p+q}\left(\prod_{\substack{i, j=1 \\
i \neq j}}^{n}\left(p a_{i}^{M}+q a_{j}^{M}\right)\right)^{\frac{1}{n(n-1)}},\right. \\
& \left.\frac{1}{p+q}\left(\prod_{\substack{i, j=1 \\
i \neq j}}^{n}\left(p a_{i}^{U}+q a_{j}^{U}\right)\right)^{\frac{1}{n(n-1)}}\right]=\left[\frac{1}{p+q}\left(\prod_{\substack{i, j=1 \\
i \neq j}}^{n}\left(\frac{p a_{i}^{L}+q a_{j}^{L}}{1+p a_{i}^{L} \cdot q a_{j}^{L}}\right)\right)^{\frac{1}{n(n-1)}},\right. \\
& \left.\frac{1}{p+q}\left(\prod_{\substack{i, j=1 \\
i \neq j}}^{n}\left(\frac{p a_{i}^{M}+q a_{j}^{M}}{1+p a_{i}^{M} \cdot q a_{j}^{M}}\right)\right)^{\frac{1}{n(n-1)}}, \frac{1}{p+q}\left(\prod_{\substack{i, j=1 \\
i \neq j}}^{n}\left(\frac{p a_{i}^{U}+q a_{j}^{U}}{1+p a_{i}^{U} \cdot q a_{j}^{U}}\right)\right)^{\frac{1}{n(n-1)}}\right]
\end{aligned}
$$


then TFEGBM ${ }^{p, q}$ is called the triangular fuzzy Einstein geometric Bonferroni mean (TFEGBM) operator.

It can be easily proved that the TFEGBM operator has the following properties.

Theorem 1. (Boundedness) Let $\tilde{a}_{i}=\left[a_{i}^{L}, a_{i}^{M}\right.$, $\left.a_{i}^{U}\right](i=1,2, \cdots, n)$ be a set of triangular fuzzy numbers, and let

$$
\tilde{a}^{-}=\min _{j} \tilde{a}_{j}, \tilde{a}^{+}=\min _{j} \tilde{a}_{j}
$$

Then

$$
\tilde{a}^{-} \leq \operatorname{TFEGBM} M^{p, q}\left(\tilde{a}_{1}, \tilde{a}_{2}, \cdots, \tilde{a}_{n}\right) \leq \tilde{a}^{+}
$$

Theorem 2. (Monotonicity) Let $\tilde{a}_{i}=\left[a_{i}^{L}, a_{i}^{M}\right.$, $\left.a_{i}^{U}\right](i=1,2, \cdots, n) \quad$ and $\quad \tilde{a}_{i}^{\prime}=\left[a_{i}^{\prime L}, a_{i}^{\prime M}, a_{i}^{\prime U}\right]$ $(i=1,2, \cdots, n)$ be two sets of triangular fuzzy numbers, if $\tilde{a}_{j} \leq \tilde{a}_{j}^{\prime}$, for all $j$, then

$$
\begin{aligned}
& \operatorname{TFEGBM} M^{p, q}\left(\tilde{a}_{1}, \tilde{a}_{2}, \cdots, \tilde{a}_{n}\right) \\
& \quad \leq \operatorname{TFEGBM} M^{p, q}\left(\tilde{a}_{1}^{\prime}, \tilde{a}_{2}^{\prime}, \cdots, \tilde{a}_{n}^{\prime}\right) .
\end{aligned}
$$

Theorem 4. (Commutativity) Let $\tilde{a}_{i}=\left[a_{i}^{L}, a_{i}^{M}\right.$, $\left.a_{i}^{U}\right](i=1,2, \cdots, n) \quad$ and $\quad \tilde{a}_{i}^{\prime}=\left[a_{i}^{\prime L}, a_{i}^{\prime M}, a_{i}^{\prime}\right]$ $(i=1,2, \cdots, n)$ be two sets of triangular fuzzy numbers, where $\tilde{a}_{i}^{\prime}=\left[a_{i}^{\prime L}, a_{i}^{\prime M}, a_{i}^{\prime U}\right](i=1,2$, $\cdots, n)$ is any permutation of $\tilde{a}_{i}=\left[a_{i}^{L}, a_{i}^{M}\right.$, $\left.a_{i}^{U}\right](i=1,2, \cdots, n)$, then

$$
\begin{aligned}
& \text { TFEGBM } \\
& \quad=\operatorname{TFEG}\left(\tilde{a}_{1}, \tilde{a}_{2}, \cdots, M^{p, q}\left(\tilde{a}_{1}^{\prime}, \tilde{a}_{2}^{\prime}, \cdots, \tilde{a}_{n}^{\prime}\right)\right.
\end{aligned}
$$

Considering that the input arguments may have different importance, here we define the triangular fuzzy weighted Einstein geometric Bonferroni mean (TFWEGBM) operator.

Definition 6. $\tilde{a}_{i}=\left[a_{i}^{L}, a_{i}^{M}, a_{i}^{U}\right](i=1,2, \cdots, n)$ be a set of triangular fuzzy numbers and $p, q>0$, $w=\left(w_{1}, w_{2}, \cdots, w_{n}\right)^{T}$ is the weight vector of $\tilde{a}_{i}=$ $\left[a_{i}^{L}, a_{i}^{M}, a_{i}^{U}\right](i=1,2, \cdots, n)$, where $w_{i}$ indicates the importance degree of $\tilde{a}_{i}$, satisfying $w_{i}>0(i=$ $1,2, \cdots, n)$, and $\sum_{i=1}^{n} w_{i}=1$. If

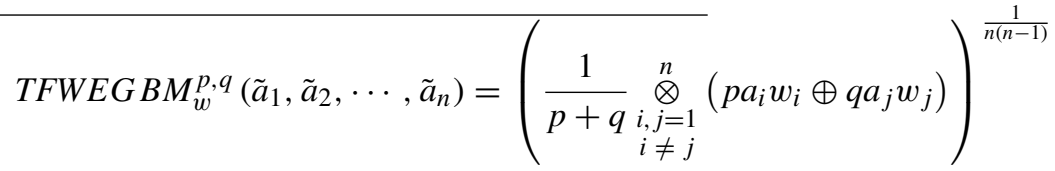

$$
\begin{aligned}
& =\left[\frac{1}{p+q}\left(\prod_{\substack{i, j=1 \\
i \neq j}}^{n}\left(p a_{i}^{L} w_{i}+q a_{j}^{L} w_{j}\right)\right)^{\frac{1}{n(n-1)}}, \frac{1}{p+q}\left(\prod_{\substack{i, j=1 \\
i \neq j}}^{n}\left(p a_{i}^{M} w_{i}+q a_{j}^{M} w_{j}\right)\right)^{\frac{1}{n(n-1)}},\right. \\
& \left.\frac{1}{p+q}\left(\prod_{\substack{i, j=1 \\
i \neq j}}^{n}\left(p a_{i}^{U} w_{i}+q a_{j}^{U} w_{j}\right)\right)^{\frac{1}{n(n-1)}}\right]=\left[\frac{1}{p+q}\left(\prod_{\substack{i, j=1 \\
i \neq j}}^{n}\left(\frac{p a_{i}^{L} w_{i}+q a_{j}^{L} w_{j}}{1+p a_{i}^{L} w_{i} \cdot q a_{j}^{L} w_{j}}\right)\right)^{\frac{1}{n(n-1)}},\right. \\
& \left.\frac{1}{p+q}\left(\prod_{\substack{i, j=1 \\
i \neq j}}^{n}\left(\frac{p a_{i}^{M} w_{i}+q a_{j}^{M} w_{j}}{1+p a_{i}^{M} w_{i} \cdot q a_{j}^{M} w_{j}}\right)\right)^{\frac{1}{n(n-1)}}, \frac{1}{p+q}\left(\prod_{\substack{i, j=1 \\
i \neq j}}^{n}\left(\frac{p a_{i}^{U} w_{i}+q a_{j}^{U} w_{j}}{1+p a_{i}^{M} w_{i} \cdot q a_{j}^{M} w_{j}}\right)\right)^{\frac{1}{n(n-1)}}\right]
\end{aligned}
$$

Theorem 3. (Idempotency) Let $\tilde{a}_{i}=\left[a_{i}^{L}, a_{i}^{M}\right.$, $\left.a_{i}^{U}\right](i=1,2, \cdots, n)$ be a set of triangular fuzzy numbers. If all $\tilde{a}_{j}\left(\tilde{a}_{j}=\left[a_{j}^{L}, a_{j}^{M}, a_{j}^{U}\right]\right)$ are equal, i.e. $\tilde{a}_{j}\left(\tilde{a}_{j}=\left[a_{j}^{L}, a_{j}^{M}, a_{j}^{U}\right]\right)=\tilde{a}\left(\tilde{a}=\left[a^{L}, a^{M}, a^{U}\right]\right)$ for all $j$, then

$$
\operatorname{TFEGBM}^{p, q}\left(\tilde{a}_{1}, \tilde{a}_{2}, \cdots, \tilde{a}_{n}\right)=\tilde{a}
$$

then $T F W E G B M_{w}^{p, q}$ is called the triangular fuzzy weighted Einstein geometric Bonferroni mean (TFWEGBM) operator.

\section{An approach to multiple attribute decision making with triangular fuzzy information}

In this section, we shall utilize the triangular fuzzy weighted Einstein geometric Bonferroni mean 
(TFWEGBM) operator to multiple attribute decision making for evaluating the psycholinguistic teaching effect with triangular fuzzy information. Let $A=\left\{A_{1}, A_{2}, \cdots, A_{m}\right\}$ be a discrete set of alternatives, $G=\left\{G_{1}, G_{2}, \cdots, G_{n}\right\}$ be the set of attributes, whose weight vector is $\omega=\left(\omega_{1}, \omega_{2}, \cdots, \omega_{n}\right)$, with $\omega_{j} \geq 0, \quad j=1,2, \cdots, n, \quad \sum_{j=1}^{n} \omega_{j}=1$. Suppose that $R=\left(\tilde{a}_{i j}\right)_{m \times n}=\left[r_{i j}^{L}, r_{i j}^{M}, r_{i j}^{U}\right]_{m \times n}$ is the decision making matrix, where $\tilde{a}_{i j}$ is the preference value, which take the form of triangular fuzzy numbers, given by the decision maker, for the alternative $A_{i} \in$ $A$ with respect to the attribute $G_{j} \in G$.

Then, we utilize the TFWEGBM operator to solve multiple attribute decision making problems for evaluating the psycholinguistic teaching effect with triangular fuzzy information, which can be described as following:

Step 1. Utilize the decision information given in matrix $\tilde{R}$, and the TFWEGBM operator (in general, we can take $p=q=1$ )
Summing all the elements in each line of matrix $P$, we have

$$
p_{i}=\sum_{j=1}^{m} p_{i j}, i=1,2, \cdots, m .
$$

Step 3. Rank all the alternatives $A_{i}(i=1,2, \cdots, m)$ and select the best one(s) in accordance with the collective overall preference values $p_{i}(i=1,2$, $\cdots, m)$.

\section{Numerical example}

The traditional way of teaching features that teachers impart knowledge to students in classrooms where students may have difficulties in good reception of knowledge due to various factors such as local environment, learning peers and other external interruptions. In fact, every kind of learning must prioritize student's knowledge acceptance, however, in many

$$
\begin{aligned}
& \tilde{r}_{i}=\left(r_{i}^{L}, r_{i}^{M}, r_{i}^{U}\right)=T F W E G B M_{w}^{p, q}\left(\tilde{r}_{i 1}, \tilde{r}_{i 2}, \cdots, \tilde{r}_{i n}\right)
\end{aligned}
$$

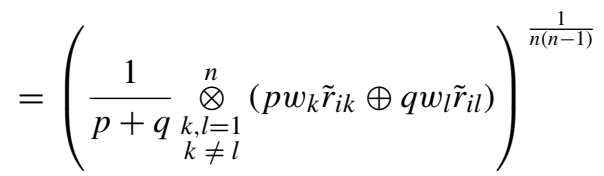

$$
\begin{aligned}
& =\left[\frac{1}{p+q}\left(\prod_{\substack{k, l=1 \\
k \neq l}}^{n}\left(p w_{k} r_{i k}^{L}+q w_{l} r_{i l}^{L}\right)\right)^{\frac{1}{n(n-1)}}, \frac{1}{p+q}\left(\prod_{\substack{k, l=1 \\
k \neq l}}^{n}\left(p w_{k} r_{i k}^{M}+q w_{l} r_{i l}^{M}\right)\right)^{\frac{1}{n(n-1)}},\right. \\
& \left.\frac{1}{p+q}\left(\prod_{\substack{k, l=1 \\
k \neq l}}^{n}\left(p w_{k} r_{i k}^{U}+q w_{l} r_{i l}^{U}\right)\right)^{\frac{1}{n(n-1)}}\right]=\left[\frac{1}{p+q}\left(\prod_{\substack{k, l=1 \\
k \neq l}}^{n}\left(\frac{p w_{k} r_{i k}^{L}+q w_{l} r_{i l}^{L}}{1+p w_{k} r_{i k}^{L} \cdot q w_{l} r_{i l}^{L}}\right)\right)^{\frac{1}{n(n-1)}},\right. \\
& \left.\frac{1}{p+q}\left(\prod_{\substack{k, l=1 \\
k \neq l}}^{n}\left(\frac{p w_{k} r_{i k}^{M}+q w_{l} r_{i l}^{M}}{1+p w_{k} r_{i k}^{M} \cdot q w_{l} r_{i l}^{M}}\right)\right)^{\frac{1}{n(n-1)}}, \frac{1}{p+q}\left(\prod_{\substack{k, l=1 \\
k \neq l}}^{n}\left(\frac{p w_{k} r_{i k}^{U}+q w_{l} r_{i l}^{U}}{1+p w_{k} r_{i k}^{U} \cdot q w_{l} r_{i l}^{U}}\right)\right)^{\frac{1}{n(n-1)}}\right] \\
& i=1,2, \cdots, m, j=1,2, \cdots, n \text {. }
\end{aligned}
$$

Step 2. To rank these overall preference values $\tilde{r}_{i}(i=1,2, \cdots, m)$, we first compare each $\tilde{r}_{i}$ with all the $\tilde{r}_{j}(j=1,2, \cdots, m)$ by using Equation (2). For simplicity, we let $p_{i j}=p\left(\tilde{r}_{i} \geq \tilde{r}_{j}\right)$, then we develop a complementary matrix as $P=\left(p_{i j}\right)_{m \times m}$, where $p_{i j} \geq 0, p_{i j}+p_{j i}=1, p_{i i}=0.5, i, j=1,2, \cdots, n$. classes, the students in the back are more likely to ignore what the teacher have transmitted in classes. In the information era, computer technology has become a great helper in bringing magic to classrooms. In the network setting, web-based learning technology can make learning transcend the con- 
Table 1

Decision matrix $A$

\begin{tabular}{ccccc}
\hline & $\mathrm{G}_{1}$ & $\mathrm{G}_{2}$ & $\mathrm{G}_{3}$ & $\mathrm{G}_{4}$ \\
\hline $\mathrm{A}_{1}$ & $(0.68,0.70,0.71)$ & $(0.63,0.66,0.68)$ & $(0.50,0.52,0.55)$ & $(0.66,0.68,0.69)$ \\
$\mathrm{A}_{2}$ & $(0.55,0.58,0.61)$ & $(0.70,0.71,0.73)$ & $(0.71,0.72,0.73)$ & $(0.70,0.72,0.73)$ \\
$\mathrm{A}_{3}$ & $(0.51,0.52,0.54)$ & $(0.51,0.52,0.54)$ & $(0.56,0.58,0.61)$ & $(0.67,0.70,0.72)$ \\
$\mathrm{A}_{4}$ & $(0.53,0.58,0.63)$ & $(0.45,0.49,0.53)$ & $(0.64,0.66,0.69)$ & $(0.35,0.38,0.41)$ \\
$\mathrm{A}_{5}$ & $(0.61,0.63,0.66)$ & $(0.40,0.50,0.56)$ & $(0.33,0.40,0.43)$ & $(0.42,0.45,0.48)$ \\
\hline
\end{tabular}

straints of time, place and learning group, facilitate cooperation among learners and bring about the best learning experiences to students. In this process, even students have troubles in understanding the courses, they still can turn to virtual learning environment at their convenience, which can ensure the required knowledge is well received. In this section, we utilize a practical multiple attribute decision making problems for psycholinguistic teaching effect evaluation to illustrate the application of the developed approaches. The expert team selects four attributes to evaluate the five possible college psycholinguistic schools: (1) $1 \mathrm{G}_{1}$ is the environment of teaching and studying; (2) $\mathrm{G}_{2}$ is the management of teaching information; (3) $_{3}$ is the curriculum design and target; (4) $\mathrm{G}_{4}$ is the empathy and the teaching practice. The five possible five possible college psycholinguistic schools $A_{i}(i=1,2, \cdots, 5)$ are to be evaluated using the triangular fuzzy numbers by the decision makers under the above four attributes (whose weighting vector is $\omega=(0.2,0.1,0.3,0.4))$, and construct the following matrix $A=\left(\tilde{a}_{i j}\right)_{5 \times 4}$ is shown in Table 1 .

In the following, in order to select the most desirable college psycholinguistic schools, we utilize the TFWEGBM operator to solve the multiple attribute decision making problems for psycholinguistic teaching effect evaluation with triangular fuzzy information, which can be described as following:

Firstly, aggregate all triangular fuzzy preference value $\tilde{r}_{i j}(j=1,2, \cdots, n)$ by using the TFWEGBM to derive the overall triangular fuzzy preference values $\tilde{r}_{i}(i=1,2,3,4,5)$ of the college psycholinguistic schools $A_{i}$.

$$
\begin{aligned}
\tilde{r}_{1} & =[0.148,0.167,0.186] \\
\tilde{r}_{2} & =[0.183,0.207,0.231] \\
\tilde{r}_{3} & =[0.204,0.225,0.241] \\
\tilde{r}_{4} & =[0.198,0.205,0.237] \\
\tilde{r}_{5} & =[0.186,0.209,0.232]
\end{aligned}
$$

Then, rank all the college psycholinguistic schools $A_{i}(i=1,2, \cdots, 5)$ in accordance with the preference degree $p_{i}(i=1,2, \cdots, 5): A_{3} \succ A_{4} \succ A_{2} \succ$ $A_{5} \succ A_{1}$, and thus the most desirable college psycholinguistic school is $A_{3}$.

\section{Conclusion}

With the booming of China's economy in the 21st century, the quality of higher education is facing many challenges, such as the grand scale of development, inadequate investment in higher education, to name a few. New challenges ahead need new moves and policy planning. Among them, how to evaluate the teaching effect becomes a critical point in teaching-learning activities. Moreover, the development of multi-disciplinary science has become a huge opportunity with which we could be enlightened. Colleges and universities must have high-quality education to develop high-quality talent. Teaching supervision plays an important role in evaluating teaching process and teaching quality. Even, it can function to help monitoring school management in colleges. Teaching assessment is a key link of teaching-effect and teaching-management. In this paper, we investigate the multiple attribute decision making problems for evaluating the psycholinguistic teaching effect with triangular fuzzy information. Motivated by the idea of geometric Bonferroni mean and Einstein operations, we develop the triangular fuzzy Einstein geometric Bonferroni mean (TFEGBM) operator and triangular fuzzy weighted Einstein geometric Bonferroni mean (TFWEGBM) operator for aggregating the triangular fuzzy information. Then, based on the TFWEGBM operator, we develop the procedure for multiple attribute decision making with the triangular fuzzy information. Finally, a practical example for evaluating the psycholinguistic teaching effect is given to verify the developed approach. In our future studies, our results may be further extended by using the traditional uncertain and fuzzy decision making theories and techniques [34-49]. 


\section{Acknowledgments}

This study is supported by the 2014 Fundamental Research Funds for the Central Universities under grant No. 3102014RW0023 and 2014 Higher Education Research Fund under grant No. 2014GJY09.

\section{References}

[1] R.H. Green and J.R. Doyle, On maximizing discrimination in multiple criteria decision making, Journal of the Operational Research Society 46(2) (1995), 192-204.

[2] R.E. Steuer and P. Na, Multiple criteria decision making combined with finance: A categorized bibliographic study, European Journal of Operational Research 150(3) (2003), 496-515.

[3] J. Wallenius, J.S. Dyer, P.C. Fishburn, R.E. Steuer, S. Zionts and K. Deb, Multiple criteria decision making, multi-attribute utility theory: Recent accomplishments and what lies ahead, Management Science 54(7) (2008), 1336-1349.

[4] G.W. Wei, Approaches to interval intuitionistic trapezoidal fuzzy multiple attribute decision making with incomplete weight information, International Journal of Fuzzy Systems 17(3) (2015), 484-489.

[5] C.W. Churchman, R.L. Ackoff and N.M. Smith, An approximate measure of value, Journal of the Operational Research Society of America 2(2) (1954), 172-187.

[6] T.L. Saaty, The analytic hierarchy process, in Proceedings of the Second International Seminar on Operational Research in the Basque Provinces 4 (1980), 189-234.

[7] C.L. Hwang and K. Yoon, Multiple Attribute Decision Making: Methods and Applications, Springer, Berlin, Germany, 1981.

[8] Z.S. Xu, A priority method for triangular fuzzy number complementary judgement matrix, System Engineer-Theory \& Practice 23(10) (2003), 86-89.

[9] X.R. Wang and Z.P. Fan, Fuzzy ordered weighted averaging (FOWA) operator and its application, Fuzzy Systems and Mathematics 17(4) (2003), 67-72.

[10] Z.S. Xu, A fuzzy ordered weighted geometric operator and its application to in fuzzy AHP, Journal of Systems Engineering and Electronics 31(4) (2002), 855-858.

[11] Z.S. Xu and D. Wu, Method based on fuzzy linguistic judgement matrix and fuzzy fuzzy induced ordered weighted averaging (FIOWA) operator for decision making problems with a limited set of alternatives, Fuzzy Systems and Mathematics 18(1) (2004), 76-80.

[12] Z.S. Xu and Q.L. Da, Method based on fuzzy linguistic scale and FIOWGA operator for decision making problems, Journal of Southeast University(English Edition) 19(1) (2003), $88-91$.

[13] Z.S. Xu, Fuzzy harmonic mean operators, International Journal of Intelligent Systems 24 (2009), 152-172.

[14] G.W. Wei, Fuzzy ordered weighted harmonic averaging operator and its application to decision making, Journal of Systems Engineering and Electronics 31(4) (2009), $855-858$.

[15] G.W. Wei, FIOWHM operator and its application to multiple attribute group decision making, Expert Systems with Applications 38(4) (2011), 2984-2989.
[16] G.W. Wei, X.F. Zhao, R. Lin and H.J. Wang, Generalized triangular fuzzy correlated averaging operator and their application to multiple attribute decision making, Applied Mathematical Modelling 36(7) (2012), 2975-2982.

[17] J.M. Merigo, Fuzzy multi-person decision making with fuzzy probabilistic aggregation operators, International Journal of Fuzzy Systems 13 (2011), 163-174.

[18] J.M. Merigo and M. Casanovas, Fuzzy generalized hybrid aggregation operators and its application in fuzzy decision making, International Journal of Fuzzy Systems 12 (2010), $15-24$.

[19] J.M. Merigo and A.M. Gil-Lafuente, Fuzzy induced generalized aggregation operators and its application in multi-person decision making, Expert Systems with Applications 38(8) (2011), 9761-9772.

[20] Z.S. Xu, Fuzzy ordered distance measures, Fuzzy Optimization and decision Making 11(1) (2012), 73-97.

[21] X. Zhao, R. Lin and G. Wei, Fuzzy prioritized operators and their application to multiple attribute group decision making, Applied Mathematical Modelling 37 (2013), 4759-4770.

[22] G. Wei, X. Zhao, H. Wang and R. Lin, Fuzzy power aggregating operators and their application to multiple attribute group decision making, Technological and Economic Development of Economy 19(3) (2013), 377-396.

[23] W.-Q. Zhu, P. Liang, L.-J. Wang and Y.-R. Hou, Triangular fuzzy Bonferroni mean operators and their application to multiple attribute decision making, Journal of Intelligent and Fuzzy Systems 29(4) (2015), 1265-1272.

[24] J. Guo, D. Fan, H. Che, Y. Duan, H. Wang and D.-W. Zhang, An approach to network security evaluation of computer network information system with triangular fuzzy information, Journal of Intelligent and Fuzzy Systems 28(5) (2015), 2029-2035.

[25] B. Zhu, Z.S. Xu and M.M. Xia, Hesitant fuzzy geometric Bonferroni means, Information Sciences 205(1) (2012), $72-85$.

[26] X.-P. Jiang and G.-W. Wei, Some Bonferroni mean operators with 2-tuple linguistic information and their application to multiple attribute decision making, Journal of Intelligent and Fuzzy Systems 27 (2014), 2153-2162.

[27] G. Wei, X. Zhao, R. Lin and H. Wang, Uncertain linguistic Bonferroni mean operators and their application to multiple attribute decision making, Applied Mathematical Modelling 37 (2013), 5277-5285.

[28] E.P. Klement, R. Mesiar and E. Pap, Triangular norms. Position paper. I. Basic analytical and algebraic properties, Fuzzy Sets and Systems 143(1) (2004), 5-26.

[29] W. Wang and X. Liu, Intuitionistic fuzzy information aggregation using einstein operations, IEEE Trans Fuzzy Systems 20(5) (2012), 923-938.

[30] X. Zhao, R. Lin and G. Wei, Hesitant triangular fuzzy information aggregation based on einstein operations and their application to multiple attribute decision making, Expert Systems with Applications 41(4) (2014), 1086-1094.

[31] S. Zhang and D. Yu, Some geometric Choquet aggregation operators using Einstein operations under intuitionistic fuzzy environment, Journal of Intelligent and Fuzzy Systems 26(1) (2014), 491-500.

[32] W. Wang and X. Liu, Some operations over atanassov's intuitionistic fuzzy sets based on einstein T-norm and T-Conorm, International Journal of Uncertainty, Fuzziness and Knowledge-Based Systems 21(2) (2013), 263-276. 
[33] P.J.M. Van Laarhoven and W. Pedrycz, A fuzzy extension of Saaty's priority theory, Fuzzy Sets and Systems 11 (1983), 229-241.

[34] L.-G. Ran and G. Wei, Uncertain prioritized operators and their application to multiple attribute group decision making, Technological and Economic Development of Economy 21(1) (2015), 118-139.

[35] B. Farhadinia, Information measures for hesitant fuzzy sets and interval-valued hesitant fuzzy sets, Information Sciences 240(10) (2013), 129-144.

[36] Z. Zhang, Hesitant fuzzy power aggregation operators and their application to multiple attribute group decision making, Information Sciences 234(10) (2013), 150-181.

[37] B. Zhu, Z. Xu and M. Xia, Hesitant fuzzy geometric Bonferroni means, Information Sciences 205 (2012), 72-85.

[38] R. Lin, X.F. Zhao and G.X. Wei, Models for selecting an ERP system with hesitant fuzzy linguistic information, Journal of Intelligent Fuzzy Systems 26(5) (2014), 2155-2165.

[39] G.R. Jahanshahloo, F.H. Lotfi and M. Izadikhah, An algorithmic method to extend TOPSIS for decision-making problems with interval data, Applied Mathematics and Computation 175(2) (2006), 1375-1384.

[40] G. Wei, R. Lin, X. Zhao and H. Wang, An approach to multiple attribute decision making based on the induced Choquet integral with fuzzy number intuitionistic fuzzy information, Journal of Business Economics and Management 15(2) (2014), 277-298.

[41] N. Chen, Z. Xu and M. Xia, Correlation coefficients of hesitant fuzzy sets and their applications to clustering analysis, Applied Mathematical Modelling: Simulation and Computation for Engineering and Environmental Systems 37(4) (2013), 2197-2211.
[42] H.M. Moshkovich, A.I. Mechitov and D.L. Olson, Ordinal judgments in multiattribute decision analysis, European Journal of Operational Research 137(3) (2002), 625-641.

[43] Z.S. Xu, Uncertain Multiple Attribute Decision Making: Methods and Applications, Tsinghua Press, Beijing, China, 2005.

[44] X. Zhao, R. Lin and G. Wei, Hesitant triangular fuzzy information aggregation based on einstein operations and their application to multiple attribute decision making, Expert Systems with Applications 41(4) (2014), 1086-1094.

[45] N. Bryson and A. Mobolurin, An action learning evaluation procedure for multiple criteria decision making problems, European Journal of Operational Research 96(2) (1997), 379-386.

[46] G.W. Wei and X. Zhao, Methods for probabilistic decision making with linguistic information, Technological and Economic Development of Economy 20(2) (2014), 193-209.

[47] G.W. Wei, Interval valued hesitant fuzzy uncertain linguistic aggregation operators in multiple attribute decision making, International Journal of Machine Learning and Cybernetics 7(6) (2016), 1093-1114.

[48] G.W. Wei, Picture fuzzy cross-entropy for multiple attribute decision making problems, Journal of Business Economics and Management 17(4) (2016), 491-502.

[49] J.-Q. Wang and Z. Zhang, Programming method of multi-criteria decision-making based on intuitionistic fuzzy number with incomplete certain information, Control and Decision 23(10) (2008), 1145-1148. 